\title{
POPULATION STUDY ARTICLE Identifying children with Special Health Care Needs in Alexandria, Egypt
}

\author{
Iman $\mathrm{H}$ Wahdan ${ }^{1}$ and Nessrin A El-Nimr ${ }^{1}$
}

BACKGROUND: In developing countries, obtaining reliable prevalence rates for children with special health care needs (CSHCN) is challenging. One of the tools used to identify CSHCN is the CSHCN Screener (not available in Arabic). The aim is to test the feasibility of using an Arabic version of CSHCN screener in identifying CSHCN in the Egyptian setup and to estimate their prevalence in Alexandria.

METHODS: A community-based survey was conducted among a representative sample of children using a multistage cluster sampling technique. A pre-designed interviewing questionnaire and the Arabic translation of CSHCN screener were used.

RESULTS: The prevalence of CSHCN was $12.2 \%$ and $91.8 \%$ of them had the three domains of health care needs. The most prevalent conditions requiring special health care were sensory and cognitive impairments and impaired mobility. Type of family was the only significant factor associated with special health care needs.

CONCLUSION: It is concluded that the screener can easily be used and help in identifying the majority of children that need to be the focus of the National health care services. It is recommended that the school health services add the screener to assist depicting the existing gaps in the health care system.

Pediatric Research (2018) 84:57-61; https://doi.org/10.1038/s41390-018-0008-x

\section{INTRODUCTION}

Children with special health care needs (CSHCN) are defined as: "those who have or are at increased risk for a chronic physical, developmental, behavioral, or emotional condition and who also require health and related services of a type or amount beyond that required by children generally." ${ }^{11}$ The care of CSHCN is becoming a significant public health issue. These children are medically complex, require services that support well beyond those that typically developing children require, and command a considerable proportion of the pediatric health care budget. $^{2}$

Historically, most research studies and health care programs for children with chronic health conditions were more vertical programs dealing with specific disease problems. Although vertical programs were successful to some extent, these programs did not comprehensively address the health care needs of CSHCN, and with the relatively low prevalence of most chronic childhood conditions, it was difficult to find adequate numbers of children with specific diagnoses to allow researchers to make statistical analysis and comparisons. ${ }^{3-5}$ Since 1990 s and with the global change in the health care systems from being composed of purely vertical programs to a welfare system addressing comprehensively the special health care needs of children due to chronic illnesses, it became important to develop a non-condition specific approach to identify children with $\mathrm{CSHCN}{ }^{6}$

Knowledge of the prevalence and characteristics of CSHCN is an essential step to understand the epidemiology of special health care needs. It is equally important to assess the required needs for preventive program planning and evaluation activities. ${ }^{7}$ Different tools were used to identify $\mathrm{CSHCN}^{8,9}$ One of them is the CSHCN screener, developed through the efforts of the Child and
Adolescent Health Measurement Initiative (CAHMI), a national collaboration coordinated by the Foundation for Accountability. ${ }^{10}$ The CSHCN Screener uses a non-condition specific approach that identifies children across a range and diversity of childhood chronic conditions and special needs. ${ }^{11}$ It identifies children with elevated or unusual needs for health care or educational services due to a chronic health condition. It focuses on health consequences a child experiences as a result of having an ongoing health condition rather than on the presence of a specific diagnosis or type of disability. It allows a more comprehensive assessment of the performance of the health care system that is attainable by focusing on a single diagnosis. ${ }^{12}$ The $\mathrm{CSHCN}$ screener is only available in English and Spanish. ${ }^{13}$

Variable prevalence rates of children with chronic health conditions were reported from different developed countries. ${ }^{14}$ In Poland (2003), the prevalence of CSHCN, using an adaptation of the CSHCN instrument, was $14.5 \% .^{15}$ In Canada (2004), $30 \%$ of parents reported that their children exhibited at least one of a list of chronic conditions, while $3.3 \%$ of parents reported that their children experienced limitations in their ability to participate in age-appropriate activities as a result of their health condition. ${ }^{16}$ Between the years 2001 and 2004, several large-scale populationbased surveys provided national estimates of the prevalence of CSHCN using the CSHCN Screener tool in the USA. ${ }^{12,17}$ According to the $2011 / 12$ National Survey, $19.8 \%$ of children aged $0-17$ years in the USA had special health care needs. ${ }^{11}$ In the UK (2010), the rate of childhood disability was $7.3 \% .^{18}$ In developing countries, obtaining reliable prevalence rates for CSHCN is a challenging task. Sophisticated datasets associated with governmental services and high-quality research studies are less common due to fewer resources. ${ }^{14}$

${ }^{1}$ Department of Epidemiology, High Institute of Public Health, Alexandria University, Alexandria, Egypt

Correspondence: Nessrin A El-Nimr (dr.elnimr@gmail.com)

Received: 9 December 2017 Revised: 16 February 2018 Accepted: 10 March 2018

Published online: 23 May 2018 
The aim of this study is to test the feasibility of using an Arabic version of the CSHCN Screener in identifying CSHCN in the Egyptian setup, to estimate the prevalence and to describe the characteristics of CSHCN in Alexandria, Egypt, using the Arabic version of the CSHCN Screener.

\section{METHODS}

A community-based survey was conducted during the first half of 2017. A multistage cluster sampling technique was used to select a representative sample of children aged 6-14 years from the 8 health districts of Alexandria after reviewing the estimated population size of these districts for the year 2016. The sample size was determined using epi info, version 7. On the basis of an estimated prevalence of CSHCN of $19.8 \%,{ }^{11}$ confidence limit of $5 \%$, and a design effect of 2 , the minimum required sample size at $95 \%$ confidence level was 488 , and it was rounded to 500 children. The final sample amounted to 501 children. They were all aged 6-14 years in the 405 selected families. For the study, in case a family refused, the first neighbor was taken in its place.

The study was approved by the Ethics Committee of the High Institute of Public Health. The researchers complied with the International Guidelines for Research Ethics. Verbal consent was obtained from the guardians of the study participants after explanation of the purpose and benefits of research. Anonymity and confidentiality were guaranteed and maintained. There was no conflict of interest.

Data about the children and their families were collected by face-to-face interview with the mothers of the studied children using a pre-designed interviewing questionnaire. If the mother was not available at the time of the interview, data were collected from the father or one of the grandparents or elder brother or sister. The questionnaire included their personal and family characteristics, in addition to the Arabic translation of CSHCN screener.

Permission to translate the questionnaire into the Arabic language was obtained from the Child and Adolescent Health Measurement Initiative. The Arabic translation of the tool was obtained using the back-translation method. Initially, the tool was translated into the Arabic language by a bilingual expert and back-translated into the original version. Next, two experts examined the front and back-translations and arrived at the final Arabic version. Any conceptual differences were resolved through consensus.

The Arabic version of the full questionnaire was then given to 10 guardians of children to test the study tool concerning the need for any modification, to identify any difficulties that may arise during data collection and to estimate the average time needed to obtain the required information for each individual included in the study.

Reliability of the translated CSHCN screener was tested using Cronbach's alpha, which was calculated to be 0.992 .

The data were sorted, coded, and analyzed using SPSS for Windows, version 21. Descriptive statistics in the form of percentages, mean, and standard deviation (SD) were calculated. Crude odds ratio with $95 \%$ confidence interval was calculated to estimate the value of certain child and family characteristics in predicting the likelihood of a positive screen. ${ }^{19}$

\section{RESULTS}

Feasibility of using an Arabic version of the CSHCN screener to identify CSHCN

The translated screener was easy to administer. It took, on an average, $30 \mathrm{~min}$ to complete the interview and administer the screener. Through the forward/backward translation of the screener and its testing on some guardians, it became clear that its questions were easily understood by the interviewed guardians
Table 1. Distribution of children according to their personal and family characteristics (Alexandria, 2017)

\begin{tabular}{|c|c|}
\hline Personal and family characteristics & No. (\%) \\
\hline \multicolumn{2}{|l|}{ District } \\
\hline Montaza & $145(28.9)$ \\
\hline East & $115(23.0)$ \\
\hline Middle & $63(12.6)$ \\
\hline West & $46(9.2)$ \\
\hline Gomrok & $19(3.8)$ \\
\hline El-Amreya & $59(11.8)$ \\
\hline Al-Agamy & $42(8.4)$ \\
\hline Borg El-Arab & $12(2.4)$ \\
\hline \multicolumn{2}{|l|}{ Child's age (in years) } \\
\hline $6-$ & $97(19.4)$ \\
\hline $8-$ & $120(24.0)$ \\
\hline $10-$ & $151(30.1)$ \\
\hline $12+$ & $133(26.5)$ \\
\hline Mean \pm SD (median) & $10.1 \pm 2.1(10)$ \\
\hline \multicolumn{2}{|l|}{ Child's sex } \\
\hline Male & $278(55.5)$ \\
\hline Female & $223(44.5)$ \\
\hline \multicolumn{2}{|l|}{ Order among siblings } \\
\hline $1 \mathrm{st}$ & $194(38.7)$ \\
\hline 2nd & $170(33.9)$ \\
\hline 3rd or more & $137(27.3)$ \\
\hline \multicolumn{2}{|l|}{ Father's education } \\
\hline Illiterate or read and write & $187(37.3)$ \\
\hline Primary or preparatory & $77(15.4)$ \\
\hline Secondary & $178(35.5)$ \\
\hline University & $59(11.8)$ \\
\hline \multicolumn{2}{|l|}{ Mother's education } \\
\hline Illiterate or read and write & $260(51.9)$ \\
\hline Primary or preparatory & 79 (15.8) \\
\hline Secondary & $131(26.1)$ \\
\hline University & $31(6.2)$ \\
\hline \multicolumn{2}{|l|}{ Family income } \\
\hline Enough and save & $108(21.6)$ \\
\hline Enough but do not save & $92(18.3)$ \\
\hline Not enough & $301(60.1)$ \\
\hline \multicolumn{2}{|l|}{ Type of family } \\
\hline Living with both parents & $489(97.6)$ \\
\hline Living with one parent & $12(2.4)$ \\
\hline
\end{tabular}

and there were no language and cultural issues that may have impacted the results. The only issue was the difference in the translation of the words "health conditions" and "medical conditions", which was not clear for some of the respondents and the interviewers had to give an explanation for the two terms to help the respondents.

Description of the study sample

Table 1 shows that the distribution of the studied children by their personal and family characteristics. The proportion of children from the various districts generally corresponded to the population size of these districts. The table also shows that those aged 6 and 7 years were $19.4 \%, 8$ and 9 years were $24.0 \%, 10$ and 11 years were $30.1 \%$, and those $12-14$ years were $26.5 \%$. The mean age of 
Table 2. Distribution of the studied children according to the different domains of health-care needs (Alexandria, 2017)

Domains of health-care needs

Dependency on prescription medicine:

Child in need of medicines or is using medicines prescribed by a physician (other than vitamins)

- The reason is a medical, behavioral or health condition $(n=59)^{\text {a }}$

- The condition has continued or is expected to continue for at least 12 months $(n=58)^{\mathrm{b}}$

Service use above that considered usual or routine:

(1) Child in need or is actually using more medical or psychological or educational services than compared to most other children of same 59 (11.8) age

- The reason is related to a medical, behavioral or health conditions $(n=59)^{\mathrm{a}}$

- The condition has continued or is expected to continue for at least 12 months $(n=58)^{\mathrm{b}}$

(2) Child in need for or under special therapy (hearing, speech or physiotherapy)

- The reason related to a medical, behavioral or health condition $(n=58)^{\mathrm{a}}$

- The condition has continued or is expected to continue for at least 12 months $(n=57)^{\mathrm{b}}$

(3) Child has a psychological, or a behavioral problem or a growth or developmental problem that requires medical advice or treatment 59 (11.8)

- This condition has continued or is expected to continue for at least 12 months $(n=59)^{\text {a }}$

Functional limitations:

Child has something that prevents or limits by any means his abilities to do things that can be done by most children of the same age

- The reason related to a medical, behavioral or health condition $(n=60)^{\mathrm{a}}$

- The condition has continued or is expected to continue for at least 12 months $(n=59)^{\mathrm{b}}$

Combined health-care needs: $(n=61)^{c}$

- Service use above that considered usual or routine

- Dependency on prescription medicine and Service use above that considered usual or routine

- Service use above that considered usual or routine and Functional limitations

- Dependency on prescription medicine and Service use above that considered usual or routine and Functional limitations

a\% calculated among those who answered yes to the main question

$\mathrm{b}_{\%}$ calculated among those who answered yes to the follow-up question

$c_{\%}$ calculated among children who had special health-care needs

Table. 3. Prevalence of the conditions requiring special healthcare among children (Alexandria, 2017)

\begin{tabular}{llc}
\hline Conditions requiring special health-care & No. (\% among all children) & \% among CSHCN \\
\hline Sensory impairments (deaf-mute, blindness, cochlear damage) & $14(2.8)$ & 23.0 \\
Cognitive impairments (mental retardation, learning disability) & $10(2.0)$ & 16.4 \\
Impaired mobility (paresis, paralysis) & $9(1.8)$ & 14.8 \\
Neurological problems (epilepsy, microcephaly) & $6(1.2)$ & 9.8 \\
Behavioral and psychiatric problems & $5(1.0)$ & 5.2 \\
Down's syndrome or autism & $5(1.0)$ & 8.2 \\
Dysarthria & $5(1.0)$ & 8.2 \\
Impaired physical development (short stature, dwarfism) & $4(0.8)$ & 6.6 \\
Chronic diseases (bronchial asthma, rheumatic fever) & $3(0.6)$ & 4.9 \\
\hline
\end{tabular}

the children was $9.6 \pm 2.1$ years. There were more males $(55.5 \%)$ than females $(44.4 \%)$, with a male to female ratio of $1.25: 1$. The children were the first child in the family in $38.7 \%$, the second child in $33.9 \%$, and the third or more in $27.3 \%$ of the studied children.

Concerning parents' education, the table also shows that as much as $37.3 \%$ of fathers were illiterates or just read and write, $15.4 \%$ completed primary or preparatory education, $35.5 \%$ completed secondary education, and $11.8 \%$ were university graduates. The education of mothers was relatively less than that of the fathers. More than half of mothers (51.9\%) were illiterates or just read and write. Those who completed primary or preparatory education were $15.8 \%$ and nearly a quarter $(26.1 \%)$ completed secondary education, while only $6.2 \%$ were university graduates.
As regards their family income, $21.6 \%$ of the interviewed parents indicated that their income is enough and they save, $18.3 \%$ mentioned that their income is just enough, while $60.1 \%$ indicated that their income is short of meeting their needs. Only $2.4 \%$ of children lived with a single parent (divorced, separated, or widowed parents).

Prevalence and characteristics of CSHCN

Out of the 501 children included in the study, 61 were identified by the screener to be CSHCN, making a prevalence of CSHCN of $12.2 \%$. Table 2 shows the distribution of the studied children according to the different domains of health care needs. It shows that the prevalence of children with dependency on prescription medicine is $11.8 \%$ andthe prevalence of children with service use above that considered usual or routine is $11.8 \%$. The prevalence of 
Table 4. Distribution of children according to the prevalence of CSHCN and their personal and family characteristics (Alexandria, 2017)

\begin{tabular}{|c|c|c|c|}
\hline $\begin{array}{l}\text { Personal and family } \\
\text { characteristics }\end{array}$ & CSHCN & $\begin{array}{l}\text { Total number of } \\
\text { children }\end{array}$ & $\begin{array}{l}\% \text { of } \\
\text { CSHCN }\end{array}$ \\
\hline \multicolumn{4}{|l|}{ District } \\
\hline Montaza & 12 & 145 & 8.3 \\
\hline East & 18 & 115 & 15.7 \\
\hline Middle & 4 & 63 & 6.3 \\
\hline West & 6 & 46 & 13.0 \\
\hline Gomrok & 5 & 19 & 26.3 \\
\hline El-Amreya & 6 & 59 & 10.2 \\
\hline Al-Agamy & 8 & 42 & 19.0 \\
\hline Borg El-Arab & 2 & 12 & 16.7 \\
\hline \multicolumn{4}{|l|}{ Child's age (in years) } \\
\hline $6-$ & 9 & 97 & 9.3 \\
\hline $8-$ & 20 & 120 & 16.7 \\
\hline $10-$ & 15 & 151 & 9.9 \\
\hline $12+$ & 17 & 133 & 12.8 \\
\hline \multicolumn{4}{|l|}{ Child's sex } \\
\hline Male & 39 & 278 & 14.0 \\
\hline Female & 22 & 223 & 9.9 \\
\hline \multicolumn{4}{|l|}{ Order among siblings } \\
\hline $1 \mathrm{st}$ & 25 & 194 & 12.9 \\
\hline $2 n d$ & 21 & 170 & 12.4 \\
\hline 3rd or more & 15 & 137 & 10.9 \\
\hline \multicolumn{4}{|l|}{ Father's education } \\
\hline Illiterate or read and write & 24 & 187 & 12.8 \\
\hline Primary or preparatory & 7 & 77 & 9.1 \\
\hline Secondary & 21 & 178 & 11.8 \\
\hline University & 9 & 59 & 15.3 \\
\hline \multicolumn{4}{|l|}{ Mother's education } \\
\hline Illiterate or read and write & 29 & 260 & 11.2 \\
\hline Primary or preparatory & 9 & 79 & 11.4 \\
\hline Secondary & 19 & 131 & 14.5 \\
\hline University & 4 & 31 & 12.9 \\
\hline \multicolumn{4}{|l|}{ Type of family } \\
\hline $\begin{array}{l}\text { Father and mother } \\
\text { together (married) }\end{array}$ & 61 & 489 & 12.5 \\
\hline $\begin{array}{l}\text { Divorced, widowed or } \\
\text { separated }\end{array}$ & 0 & 12 & 0.0 \\
\hline \multicolumn{4}{|l|}{ Family income } \\
\hline Enough and save & 17 & 108 & 15.7 \\
\hline Enough but do not save & 11 & 92 & 12.0 \\
\hline Not enough & 33 & 301 & 11.8 \\
\hline
\end{tabular}

children with functional limitations was $12 \%$. The table also shows that among these domains, in almost all children, the reason was medical, behavioral, or health condition (98.3\%), and the condition has continued or is expected to continue for at least 12 months in all children. Among CSHCN, the majority (91.8\%) had these three domains combined.

Table 3 illustrates the most prevalent conditions requiring special health care. Sensory impairments ranked the first with a prevalence of $2.8 \%$, which represented $23 \%$ of the conditions, followed by cognitive impairments with a prevalence of $2 \%$, representing $16.4 \%$ of all conditions requiring special health care. Impaired mobility was the third most common condition requiring special care with a prevalence of $1.8 \%$. Other conditions included
Table 5. Crude odds ratio of special health care needs among children aged 6-14 years and their personal and family characteristics (Alexandria, 2017)

\begin{tabular}{lll}
\hline Personal and family characteristics & cOR & $95 \% \mathrm{Cl}$ \\
\hline Child's age (from $6-<10$ vs. 10+) & 1.21 & $0.71-2.08$ \\
Sex (males vs. females) & 1.49 & $0.86-2.60$ \\
Order among siblings (1st vs. others) & 1.11 & $0.65-1.92$ \\
Father's education (illiterate or read and write vs. & 1.12 & $0.64-1.91$ \\
others) & 0.93 & $0.31-2.76$ \\
Mother's education (university vs. others) & $0.88^{\mathrm{a}}$ & $0.85-0.91$ \\
Type of family (living with both parents vs. others) & 0.76 & $0.44-1.29$ \\
Family income (not enough vs. others) & & \\
\hline a Significant $(p<0.05)$ & & \\
\hline
\end{tabular}

neurological problems, behavioral and psychiatric problems, and impaired physical development, being of a prevalence of nearly $1 \%$ each and representing nearly $8 \%$ among CSHCN. Chronic diseases had the least prevalence (0.6\%) and represented $4.9 \%$ of all conditions requiring special health care.

It could be noticed from Table 4 that the highest prevalence rates of CSHCN were from Gomrok district (26.7\%), followed by Borg El Arab (16.7\%), East district (15.7\%), and the lowest prevalence rate was among children from the Middle district (6.3\%). The proportion of CSHCN was one and half times more in male children than female children. There is no special pattern observed with respect to parents' education. The prevalence rates were higher among families that reported having enough income.

Table 5 shows the association between the special health care needs among children and their personal and family characteristics presented as COR and $95 \%$ confidence interval. CSHCN were more likely to be in the younger age group (6- $<10$ years), to be males, to be the first in order among their siblings, and to have an illiterate or just read and write father. On the other hand, CSHCN were less likely to have a university educated mother, to be living with both parents, and to be from a family without enough income. The only significant factor was the type of family ( $\mathrm{COR}=$ $0.88,95 \% \mathrm{Cl}=0.85-0.91)$.

\section{DISCUSSION}

The non-condition specific approach adopted in the CSHCN screening identifies children across the wide range of chronic childhood diseases and special needs, and hence allows a comprehensive assessment of the health needs and performance of the health care system, especially as CSHCN use the health care services more than other children.

The current study shows that nearly $12 \%$ of the children aged 6-14 years in Alexandria have a chronic condition that results in increase in the use of health services or a limitation in normal activities. This rate is near to that reported from the USA in 2011/ 2012 , where $19.8 \%$ of children aged $0-17$ years require special health care needs. ${ }^{11,20}$ A much higher rate was reported in 2004 in Canada, where an estimated total of $30.3 \%$ of Canadian children aged 6-11 years had one or more chronic physical health conditions/impairments, ${ }^{16}$ while the rate of childhood disability in the UK in 2010 was reported to be $7.3 \% .^{18}$

The prevalence of CSCHN showed some variations between the various health districts in Alexandria, with a rate as low as $6.3 \%$ to a rate as high as $26.3 \%$ in another district. Similar differences were reported in the United States, where the prevalence ranged between $14.4 \%$ and $26.4 \%$ across the 50 states and the district of Columbia. ${ }^{21}$ 
There was no specific pattern for the age of CSHCN in the present study. Findings from other studies showed an increase in the rate of CSHCN by the increase in age. ${ }^{11,18,20}$ The current study showed higher prevalence of CSHCN in males, with a male to female ratio of 1.25:1. Similar results were observed from the USA study (2004) being 1.48:121 and from the UK study being 1.6:1. ${ }^{18}$

In the current study, only a very small proportion of the studied children were living in families where parents were divorced, separated, or widowed. None of these children were found to be with special health care needs. The study in Canada showed that children living with one parent were significantly more likely to have activity-limiting conditions/impairments than those living with both the parents. ${ }^{16}$ Another study in the UK reported that the proportion of disabled children living in lone parents families was significantly greater than that for non-disabled children. ${ }^{18}$ Unexpectedly, the present study showed that CSHCN were less likely to be from poorer families. An opposite finding was reported in the UK study. ${ }^{18}$

With respect to the prevalence of conditions requiring special health care services, the present study showed a relatively high proportion of children with sensory impairments (deaf-mute, blindness, and cochlear damage), cognitive impairments (mental retardation and learning disabilities), and impaired mobility (paresis and paralysis). These findings underscore the importance of these conditions and the needs for both preventive and curative services for them.

The limitations of the study included

- Reliance on parents' reports on medical conditions and on activity limitations.

- Children with chronic diseases may not be captured by the screener, particularly when these diseases do not result in activity limitation.

\section{CONCLUSION AND RECOMMENDATIONS}

The current study showed the feasibility to use the CSHCN screener in the Egyptian National health care services to identify CSHCN. The screener can easily identify the majority of children that need to be the focus of the National health care services. It could also be an easy tool to assess the quality of the ongoing school health programmes in responding to the overall needs of school children.

With the present Egyptian policy of reform giving special attention to people in need, particularly sensitive groups such as school children, it becomes important to easily identify children with special or unusual needs for health care or educational services. It is therefore recommended that the school health services, in addition to the ongoing diagnostic, preventive and curative services add an additional measure, namely the screener for CSHCN, which is a simple andeasily administered screening tool, which will also assist to depict the existing gaps in the health care system to ensure being comprehensive.

\section{ADDITIONAL INFORMATION}

Competing interests: The authors declare no competing interests.

Publisher's note: Springer Nature remains neutral with regard to jurisdictional claims in published maps and institutional affiliations.

\section{REFERENCES}

1. McPherson, M. et al. A new definition of children with special health care needs. Pediatrics 102, 137-140 (1998).

2. Goldson, E. et al. Guidelines for the care of the child with special health care needs. Adv. Pediatr. 53, 165-182 (2006).

3. Garrett, B., Davidoff, A. \& Yemane, A. Effects of medicaid managed care on health services access and utilization. Health Serv. Res. 38, 575-594 (2003).

4. Aron, L. Y., Loprest, P. J. \& Steuerle, C. E. Serving Children and Disabilities: A Systematic Look at the Programs. (Urban Institute Press, Washington DC, 1996).

5. Blumberg, L. J., Dubai, L. \& Norton, S. A. Did the medical expansions for children displace private insurance? An analysis using SIPP data. J. Health Econ. 19, 33-60 (2000).

6. Bethell, C. D. et al. Identifying children with special health care needs: development and evaluation of a short screening instrument. Ambul. Pediatr. 2, 38-47 (2002).

7. Association of Maternal and Child Health Programs (AMCHP). Reaching the Children: The Relationship between Title V and Part C. (AMCHP, Washington, DC, 2003; 9 p).

8. Newacheck, P. W. et al. An epidemiologic profile of children with special health care needs. Pediatrics 102, 117-123 (1998)

9. Stein, R. E. K. \& Silver, E. J. Operationalizing a conceptually based noncategorical definition. A first look at U.S. children with chronic conditions. Arch. Pediatr. Adolesc. Med. 153, 68-74 (1999).

10. Child and Adolescent Health Measurement Initiative. The children with special health care needs (CSHCN) screener. (CAHMI, Baltimore, 1998; 10p).

11. Child and adolescent initiative. Who are children with special health care needs (CSHCN). (CAHMI, Baltimore, 2012; 2p.

12. Bethell, C. D. et al. Comparison of the children with special health care needs screener to the questionnaire for identifying children with chronic conditions-revised. Ambul. Pediatr. 2, 49-57 (2002).

13. Read, D. et al. An evaluation of the linguistic and cultural validity of the Spanish language version of the children with special health care needs screener. Matern. Child. Health J. 11, 568-585 (2007).

14. Kennedy, P. editor. The Oxford Handbook of Rehabilitation Psychology. (Oxford University Press, Oxford, New York, 2012; 171-188).

15. Mazur, J. Adaptation of CSHCN instrument for the use in assessing the prevalence of chronic diseases in children and adolescents in Poland. Przegl. Epidemiol. 63, 137-142 (2009).

16. McDougall, J. et al. Chronic physical health conditions and disability among Canadian school-aged children: a national profile. Disabil. Rehabil. 26, 35-45 (2004).

17. Van Dyck, P. et al. The national survey of children with special health care needs. Ambul. Pediatr. 2, 29-37 (2002).

18. Blackburn, C. M., Spencer, N. J. \& Read, J. M. Prevalence of childhood disability and the characteristics and circumstances of disabled children in the UK: secondary analysis of the Family Resources Survey. BMC Pediatr. 10, 21 (2010).

19. Daniel, W. W. Biostatistics: A Foundation for Analysis in Health Sciences. 7th ed (John Wiley and sons, New York, Toronto, 1999).

20. Child and Adolescent Health Measurement Initiative (CAHMI). 2011/12 National Survey of Children's Health. Child Health Indicator and Subgroups SAS Codebook, Version 1.0. Data Resource Center for Child and Adolescent Health.

21. Davidoff, A. J. Child health. Identifying children with special health care needs in the National interview survey: a new resource for policy analysis. Health Serv. Res. 39, 53-71 (2004) 